\section{Picture stimuli for the Apple II computer}

\author{
KENNETH A. PRILL \\ University of Missouri, Columbia, Missouri
}

Picture stimuli are often of interest in psychological research, but can sometimes be cumbersome to present and manipulate with traditional media. Computers offer great flexibility in presentation and manipulation of visual stimuli; furthermore, direct computer control of stimuli allows easy integration of stimulus conditions with response collection, storage, and analysis by computer. However, implementation of pictorial stimuli on a computer can require considerable effort. The widespread availability of inexpensive Apple II microcomputers, which have relatively good graphics, makes such an effort worthwhile. Accordingly, a developmental effort has been completed for 73 pictures of familiar objects. In addition, a number of demonstration programs that present and manipulate the picture files have been developed. This paper describes the product of this effort.

Description of Pictures. The 73 pictures are based on a subset of the 260 drawings of familiar objects provided by Snodgrass and Vanderwart (1980). These stimuli are especially useful because normative ratings are available on a number of dimensions. For current purposes, the stimuli were selected on the basis of three of these properties: name agreement, image agreement, and visual complexity. Snodgrass and Vanderwart determined name agreement by instructing subjects to "identify each picture as briefly and unambiguously as possible by writing only one name, the first name that came to mind" (p.182). Image agreement was determined by asking subjects to "judge how closely each picture resembled their mental image of the object .... A rating scale of 1 indicated low agreement, that the picture provided a poor match to their image, and a rating of 5 indicated high agreement" (p. 183). For visual complexity, the subjects were instructed to "rate the complexity of each picture on a 5-point scale in which 1 indicated very simple and 5 indicated very complex. Complexity was defined as the amount of detail or intricacy of line in the picture" (p. 183).

The pictures selected for computer implementation had high name agreement (ratings greater than 75\%), high image agreement (ratings greater than 3), and moderate visual complexity (ratings between 1.5 and 3.5 ). Further subjective criteria were also applied, such as ease of creation with computer graphics and minimal intraset confusability. Seventy-three pictures that met these criteria have been developed on the computer;

The author's mailing address is: Department of Psychology, University of Missouri, Columbia, MO 65211.
Table 1

List of Available Pictures

\begin{tabular}{llll}
\hline Anchor & Cup & Kite & Screwdriver \\
Apple & Desk & Lamp & Seal \\
Arm & Dog & Leaf & Shoe \\
Ashtray & Door & Lightbulb & Sled \\
Axe & Donkey & Lock & Snail \\
Balloon & Ear & Mouse & Snowman \\
Barrel & Flag & Mushroom & Sock \\
Bed & Flower & Pants & Stool \\
Belt & Foot & Peanut & Toaster \\
Bird & Football & Penguin & Umbrella \\
Book & Fork & Pig & Wagon \\
Broom & Frog & Pipe & Watch \\
Brush & Garbage Can & Pitcher & Whistle \\
Candle & Goat & Pliers & \\
Carrot & Grapes & Plug & \\
Cat & Hammer & Pot & \\
Chair & Hand & Rabbit & \\
Chicken & Hat & Saw & \\
Clothespin & Ironing Board & Scissors & \\
Comb & Key & Screw & \\
\hline
\end{tabular}

their names are listed in Table 1. Within the limits of the resolution of the graphics system, the pictures are reasonably faithful to the original Snodgrass and Vanderwart (1980) drawings; hence, the published ratings should be applicable to the computer versions.

Each picture was scaled to fit in a $130 \times 130$ pixel rectangle within the $280 \times 192$ matrix available with the Apple II high-resolution graphics. (Due to distortion present in most monitors, the $130 \times 130$ rectangle typically results in a display that has the vertical distance being somewhat greater than the horizontal distance.) All pictures were plotted in $\mathrm{HCOLOR}=3$, that is, white; however, because the pictures have been relocated on the screen, use of a color monitor results in a multihued image (the peculiarities of Apple II high-resolution color graphics are described in the $A p$ ple II Reference Manual (1979, p. 19).

Description of Programs. In addition to the 73 picture files, a number of Applesoft BASIC demonstration programs have been developed. One program simply presents the pictures. Another program converts a high-resolution picture into $\mathrm{x}-\mathrm{y}$ coordinates; these coordinates can be used with other programs to move the picture to a different screen location, to change the picture's scale, to rotate the picture, or to degrade the picture (i.e., randomly remove an arbitrary percentage of the picture's pixels). Furthermore, the coordinates allow potential communication/transfer of the picture to another computer system.

Hardware Requirements. The minimum system required is an Apple II Plus (48K) with DOS 3.3 and Applesoft BASIC. It is recommended that a highquality monochrome (e.g., white or green phosphor) display monitor be used (problems with the use of a 
color monitor were noted above; also, television sets generally result in a low-grade picture). The program has also been tested on the Apple IIe.

Availability. The 73 pictures and associated programs can be obtained from Kenneth A. Prill, Department of Psychology, University of Missouri, Columbia, Missouri 65211. Please enclose $\$ 5.00$ to cover disk and mailing costs.

\section{REFERENCES}

APPle Computer, Inc. (1979). Apple II reference manual. Cupertino, CA: Author.

Snodgrass, J. G., \& Vanderwart, M. A. (1980). A standardized set of 260 pictures: Norms for name agreement, image agreement, familiarity, and visual complexity. Journal of Experimental Psychology: Human Learning and Memory, 6, 174-215.

(Manuscript accepted for publication March 13, 1984.) 